\title{
The impact of Bacillus megaterium on the solubilisation of phosphorus from sewage sludge
}

\author{
Joanna Ciopińska ${ }^{1, *}$, Elżbieta Bezak-Mazur ${ }^{1}$, Renata Stoińska $^{1}$, Bartosz Szeląg ${ }^{l}$ \\ ${ }^{1}$ The Faculty of Environmental, Geomatic and Energy Engineering, Kielce University of Technology, al. Tysiąclecia Państwa \\ Polskiego 7, 25-314 Kielce
}

\begin{abstract}
The aim of this work was to analyse the influence of Bacillus megaterium bacteria on the solubilisation of phosphorus in a sewage sludge. The tests were carried out for two different temperature conditions, i.e. 21 and $36^{\circ} \mathrm{C}$. In the experiment, lasting 23 days, the course of phosphorus solubilization under the influence of a changing population of bacteria was determined using Golterman's speciation analysis. This method allows to estimating the fraction of bioavailable phosphorus in the tested samples. The obtained results allow one to state that the population size of Bacillus megaterium bacteria changes, while the intensity of these changes depends on temperature and organic acids produced in metabolic processes change the $\mathrm{pH}$ of the environment, which affects phosphorus solubilisation and its speciation. The increase in the population of bacteria is accompanied by the increase in bioavailable phosphorous forms, and thus the release of phosphorus contained in the form of sparingly soluble forms in soil. The above fact is extremely important when considering the use of sewage sludge for natural purposes.
\end{abstract}

\section{Introduction}

Excessive amounts of insoluble forms in relation to soluble phosphorus in soil are an environmental problem. It was found that even in soils rich in phosphorus, only a small part of this is available for plants, i.e. about $0.1 \%$ $[7,8]$. Phosphorus, unlike other macro-elements, is assimilated by plants only in a soluble form, i.e. HPO4 ${ }^{2-}$ ions. The mobility of phosphorus in the soil is limited, which is due to the fact that it is not very accessible to living organisms. In addition, the production costs of chemical fertilisers are high, and due to the ending of phosphate resources, their use becomes imperative. Therefore, the possibility of using insoluble phosphorus contained in soil and sewage sludge is being sought. Dissolution of phosphates in the soil with the participation of microorganisms is conditioned by the secretion of low molecular weight organic acids, accompanied by a decrease in the ambient $\mathrm{pH}$. Bacteria of the genus Bacillus megaterium belong to gram positive bacteria and naturally occur in the soil. They may also be found in marine waters, bottom sediments or even rice fields $[1,11]$. These microorganisms are not pathogenic strains; therefore, they do not pose a threat to human and animal health $[3,6,10]$. Phosphate dissolving bacteria (PSB) have the ability to reduce the $\mathrm{pH}$ of the environment through the production of organic acids [7]. Bacillus megaterium have the ability to synthesise organic acids, i.e. citric, lactic or propionic acid. These acids can dissolve phosphates by ion exchange, or chelate $\mathrm{Ca}, \mathrm{Fe}$ or $\mathrm{Al}$ ions bound to phosphates [15]. As a consequence, acidification of microbial cells and their environment leads to the release of phosphorus ions from mostly inaccessible forms. Due

\footnotetext{
* Corresponding author: j.k.ciopinska@gmail.com
}

to this fact, Bacillus megaterium bacteria are included in the group of PSB (Phosphorus Solubilising Bacteria) microorganisms. These species have the natural potential to dissolve phosphorus, both organic and inorganic [12]. Particular attention is focused on microorganisms that solubilise mineral phosphorus. Solubilisation is the transformation of inorganic forms that are hard to access to bioavailable. Using them as inoculums allows for an increase in the uptake of this element by plants. These properties are of interest to the biotechnology industry [ 8 , 9].

The aim of the present research was to select appropriate conditions for phosphorus solubilisation in sewage sludge, which would allow for effective recovery of phosphorus from them. For this purpose, bacteria of the genus Bacillus megaterium naturally occurring in soil were used.

\section{Materials and methods}

The primary sewage sludge from a mechanical and biological sewage treatment plant with a hydration of $70 \%$ was used. Processing of the sludge is performed using the activated sludge method, taking into account nitrification, denitrification, biological and chemical dephosphatation. Mesophilic fermentation of sewage sludge separated in settling tanks is carried out in closed fermentation chambers. The stabilized sludge is mechanically dewatered on the belt presses and then dried in a column dryer. After the stabilization the sewage sludge was submitted to hygienisation with a dose of $0.2 \mathrm{~kg} \mathrm{CaO} / \mathrm{kg} . \mathrm{d} . \mathrm{m}$. This selected dose allowed for effective hygienisation of the tested material $[4,13]$. 
Subsequently, a medium that did not contain phosphorus was prepared [10]. The Bacillus megaterium bacteria were first applied to the previously sterilised medium, and then the whole was mixed in a rotary shaker. In a further step, $0.5 \mathrm{~g}$ of a previously homogenised sludge was weighed into each $200 \mathrm{cc}$ flask, and then $150 \mathrm{ml}$ of the medium was poured. The 48 samples in two replications were prepared in this way and divided into two parts. The first part was placed at $36^{\circ} \mathrm{C}$, and the second was placed in a laminar chamber at $21^{\circ} \mathrm{C}$ throughout the period of 23 days. During the experiment, the following analyses were performed:

- changes in the $\mathrm{pH}$ value in the tested suspension,

- number of mesophilic bacteria,

- number of bioavailable phosphorus forms in sludge,

- analysis of IR spectra of sludge.

\subsection{Changes in the $\mathrm{pH}$ value in the tested suspension}

The $\mathrm{pH}$ of all samples was measured daily. In the initial phase of the process, the $\mathrm{pH}$ was measured at $2-4 \mathrm{~h}$ intervals, and at the end of the study, once a day. The METLER TOLEDO $\mathrm{pH}$ meter was used for this purpose. To estimate the parameters of the dot plot for $21^{\circ} \mathrm{C}$, shown in Fig. 2, "Solver" was used, i.e. a tool used for parameter optimisation and estimation, implemented in the "Excel" program and described by the following formula:

$\mathrm{pH}=$

$=\left(\mathrm{pH}_{\max }-\mathrm{pH}_{0}\right) *\left(\left(\mathrm{t} / \mathrm{t}\left(\mathrm{pH}_{\max }\right)\right)^{0.913}\right) * \exp \left(-0.913 *\left(\mathrm{t} / \mathrm{t}\left(\mathrm{pH}_{\max }\right)-1\right)\right.$

where:

$\mathrm{pH}_{0}$ - initial $\mathrm{pH}$ of the suspension tested, [-];

$\mathrm{pH}_{\max }-$ maximum $\mathrm{pH}$ of the suspension tested, [-]; $\mathrm{t}-2.68,[-]$.

\subsection{Number of mesophilic bacteria}

The analysis was carried out using serial dilutions. For this purpose, $1 \mathrm{ml}$ of suspension was collected each day for 14 days from each of the flasks, previously mixed using a Sky line shaker. The prepared suspension was introduced by a pipette into a Petri dish and poured into a liquid nutrient broth and incubated at $36^{\circ} \mathrm{C}$ for 24 hours. Finally, bacterial colonies were counted and the result was calculated depending on the dilution of the suspension. After incubation, bacterial colonies were counted, and the result was calculated depending on the dilution of the suspension. Dilutions were carried out four times for each trial [11].

\subsection{Number of bioavailable phosphorus forms in sludge}

The modified sequential extraction scheme according to Golterman[3] was used to determine individual fractions of phosphorus contained in the studied sewage sludge. This method uses chelate reagents for analysis, i.e. CaEDTA and Na-EDTA, as well as solutions of sulphuric acid (VI) and sodium hydroxide $\left(\mathrm{H}_{2} \mathrm{SO}_{4}\right.$ and $\left.\mathrm{NaOH}\right)$. The chelating reagents reduce the fractionation time and prevent the $\mathrm{pH}$ from changing. The phosphorus compounds contained in the tested sediment are not hydrolysed and dissolved. Compilation of these extractants makes it possible to isolate both organic and inorganic phosphorus forms. The Ca-EDTA and $\mathrm{Na}-$ EDTA fractions make it possible to isolate inorganic compounds, while the $\mathrm{H}_{2} \mathrm{SO}_{4}$ and $\mathrm{NaOH}$ isolate organic forms of this element [2]. The extraction takes place in four stages, where after each extraction step, the analyte is filtered and treated with another extractor. The extraction scheme is shown in Table 1.

Table 1. Modified scheme of sequential extraction of phosphorus according to Golterman

\begin{tabular}{|c|c|c|}
\hline Stage & $\begin{array}{c}\text { Extraction } \\
\text { forms }\end{array}$ & Fraction \\
\hline 1 & $\begin{array}{c}0.05 \mathrm{M} \mathrm{Ca}- \\
\text { EDTA, } \\
4 \mathrm{~h}\end{array}$ & $\begin{array}{c}\text { Phosphorus associated with } \\
\text { iron, aluminium and manganese } \\
\text { oxides and hydroxides }\end{array}$ \\
\hline 2 & $\begin{array}{c}0.1 \mathrm{M} \mathrm{Na}- \\
\text { EDTA, } \\
18 \mathrm{~h}\end{array}$ & $\begin{array}{c}\text { Phosphorus associated with } \\
\text { carbonates }\end{array}$ \\
\hline 3 & $\begin{array}{c}0.5 \mathrm{M} \mathrm{H}_{2} \mathrm{SO}_{4}, \\
2 \mathrm{~h}\end{array}$ & $\begin{array}{c}\text { Phosphorus occurring in the } \\
\text { soluble connections with organic } \\
\text { matter }\end{array}$ \\
\hline 4 & $\begin{array}{c}2 \mathrm{M} \mathrm{NaOH}, \\
2 \mathrm{~h}\end{array}$ & $\begin{array}{c}\text { The remaining phosphorus, } \\
\text { including phosphorus connected } \\
\text { with aluminosilicates, as well as } \\
\text { those contained in the organic } \\
\text { matter in the form of connections } \\
\text { which are not affected by sulphuric } \\
\text { acid in stage 3 }\end{array}$ \\
\hline
\end{tabular}

The Ca-EDTA fraction was identical to the phosphorus assimilated by microorganisms, and the sum of the Ca-EDTA and Na-EDTA fractions allowed us to determine the amount of phosphorus-bioavailable forms in the tested suspension $[1,2]$.

\subsection{Analysis of IR spectra of sludge}

Spectroscopic analysis was performed using a Perkin Elmer FTIR spectrometer. The test suspension was subjected to gravity sedimentation and then brought to an air-dry state. The sample prepared in this way was placed on the ATR attachment (Attenuated Total Reflection) containing a single crystal, which ensures multiple internal reflection of the absorbed beam $[2,17]$.

\section{Results and discussion}

\subsection{Changes in the $\mathrm{pH}$ value in the tested suspension}

During the 23 days of testing, a significant decrease in $\mathrm{pH}$ was observed. The sludge subjected to the tests was heavily hygienised, which is why the initial $\mathrm{pH}$ value ranged from 9.69 to 10 . The test samples during the experiment were not subjected to the mixing process. In the suspension held in the incubator after the first day of the experiment, the $\mathrm{pH}$ dropped by approx. 3 units, and at the turn of the eighth and ninth days of the reaction, the 
$\mathrm{pH}$ dropped by another 3 units and remained at a similar level to the end of the study (Fig.1). The jumps in $\mathrm{pH}$ during the process at $36^{\circ} \mathrm{C}$, shown in the graph (Fig. 1), can be explained by the fact that Bacillus megaterium bacteria belong to mesophilic microorganisms, which translated into acceleration of the multiplication process compared to microorganisms placed at a lower temperature. In addition, due to the fact that the mixture was highly heterogeneous and contained large amounts of calcium oxide used for hygienisation, during the digestion of the sediment by these microorganisms, they were temporarily immobilised. In the case of the suspension stored in the laminar chamber, the process took place much slower, as only on the ninth day of the experiment was there a diametric drop in the $\mathrm{pH}$, which slightly changed at the end of the observations (Fig. 2). The bacteria used for research produce organic acids, such as lactic, citric or propionic acid, which probably caused the large change in $\mathrm{pH}$. The process came much faster at a higher temperature, since a temperature increase stimulates the microorganisms, which stimulates the metabolic processes by increasing enzyme activity [14,16]. The observation of changes for individual temperature conditions is shown in Figures 1 and 2 .

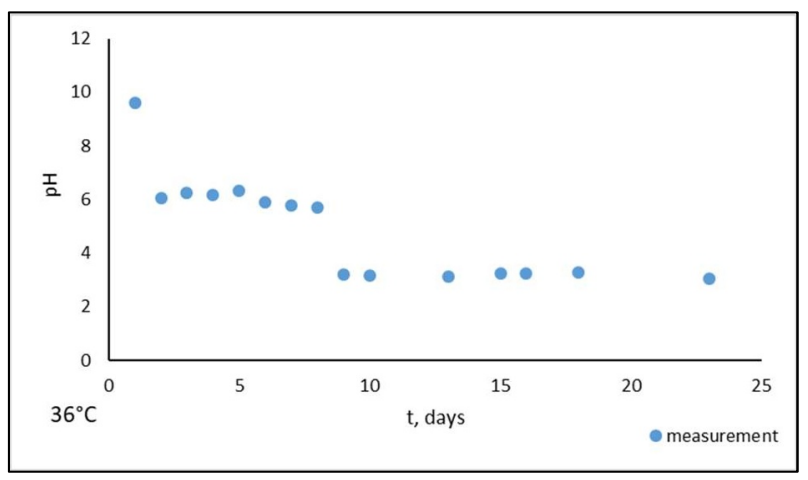

Fig. 1. Changing the $\mathrm{pH}$ value during the process at $36^{\circ} \mathrm{C}$

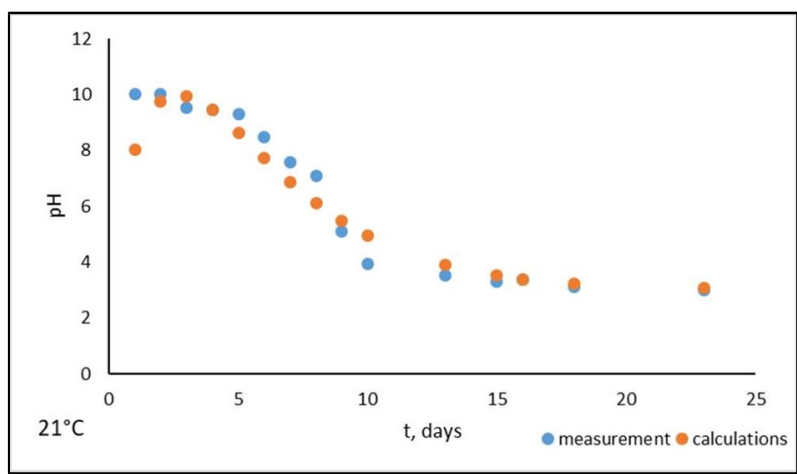

Fig. 2. Changing the $\mathrm{pH}$ value during the process at $21^{\circ} \mathrm{C}$

\subsection{Number of mesophilic bacteria}

Mesophilic microorganisms develop best at a temperature for warm-blooded organisms, i.e. $35-37^{\circ} \mathrm{C}$ $[1,5] . T h e$ mesophyll also includes the Bacillus megaterium strain. Therefore, conducting the experiment at two different temperatures, beneficial for bacteria $\left(36^{\circ} \mathrm{C}\right)$ and less favourable $\left(21^{\circ} \mathrm{C}\right)$, showed the diversity of the population of microorganisms (Fig. 3 and 4).

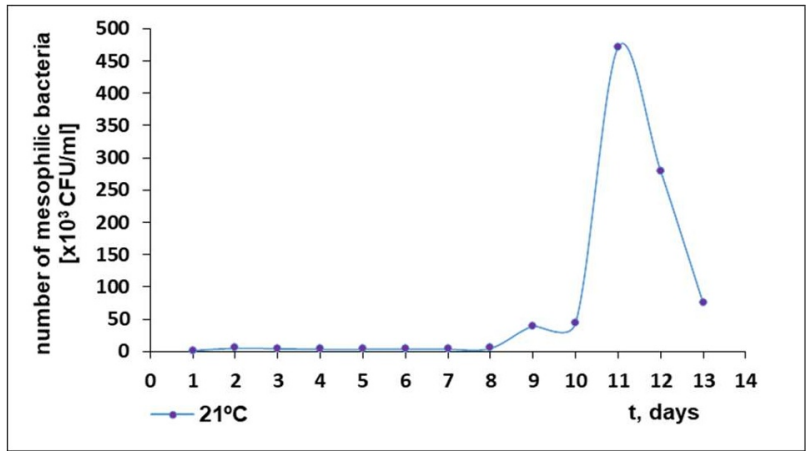

Fig. 3. The number of mesophilic bacteria cultured at $21^{\circ} \mathrm{C}$ during the tests

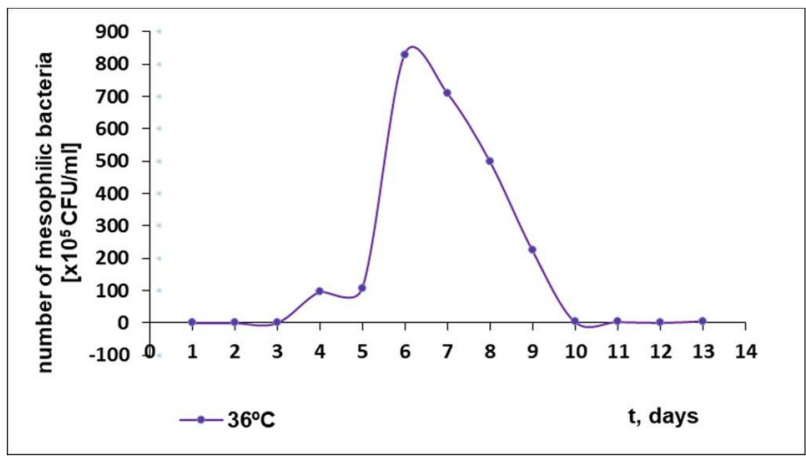

Fig. 4. The number of mesophilic bacteria cultured at $36^{\circ} \mathrm{C}$ during the tests

Comparison of these results allows us to conclude that at a temperature of $36^{\circ} \mathrm{C}$, the bacteria multiply faster, and there are definitely more of them than the microorganisms grown at $21^{\circ} \mathrm{C}$. In addition to temperature, additional adverse factors were: high initial $\mathrm{pH}$ caused by a high dose of $\mathrm{CaO}$ used for hygienisation and no mixing. The H.G. Schlegel [14] Known literature sources give exemplary stages of bacterial growth, which allowed us to describe the individual development phases for the Bacillus megaterium strain (Fig.5).

Phase I is the stagnation phase. Bacteria at this stage adapt to the new environment. The number of ribosomes and the RNA content are increased. The length of this process depends on the conditions in which the microorganisms are located. In the case of cultivation at $21^{\circ} \mathrm{C}$, the stagnation phase lasted 9 days, and at $36^{\circ} \mathrm{C}-4$ days.

Phase II - the phase of logarithmic growth, is characterised by intensive metabolism, followed by cell division. The number of bacteria increases in exponential progress. In this phase of growth, microorganisms are the most sensitive to environmental factors. In both cases, i.e. $21^{\circ} \mathrm{C}$ and $36^{\circ} \mathrm{C}$, this phase lasted 3 days.

Phase III - the phase of equilibrium, is characterised by a constant level of cell number. As a result of insufficient amounts of nutrients, the cells exhaust their own back-up material. At $21^{\circ} \mathrm{C}$, this phase lasted less than 24 hours, and at $36^{\circ} \mathrm{C}-1$ day.

Phase IV is the phase of dieback. The number of living cells is decreasing, and the processes of self-dissolution 
of bacteria under the influence of their own enzymes begin. Cell division does not occur. This stage at $36^{\circ} \mathrm{C}$ lasted about 3 days, while at $21^{\circ} \mathrm{C}$, it did not come to an end in the planned duration of the experiment.
Phase V - sleep phase, i.e. the stage at which the cells died out. Some of them change into spore forms. For a higher temperature of the process, this stage occurred after 11 days, whereas for the lower temperature, this stage was not observed $[1,3,5]$.

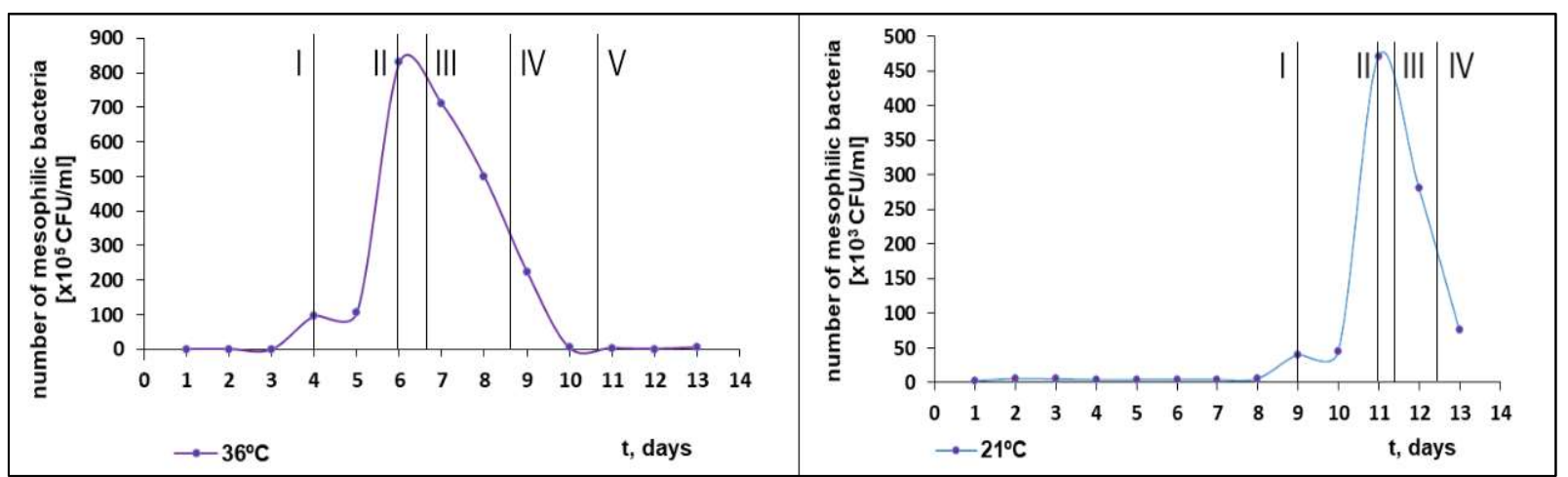

Fig. 5. Growth phases of mesophilic bacteria in suspension at a temperature of 21 and $36^{\circ} \mathrm{C}$ (I - stagnation phase, II - growth phase, III - equilibrium phase, IV - phase of dieback, V - sleep phase)

Analysis of the presented results allows us to conclude that in both cases, the multiplication of microorganisms occurs very rapidly. It is true that at a lower temperature, the stagnation phase lasts much longer; however, when the microorganisms are adapted to a given environment, the process is more efficient. A quick transition from the equilibrium phase to the dieback phase can be caused by the production of organic acids, which lowered the $\mathrm{pH}$ to approx. 3. Such acidic reaction of the environment may not be favourable for microorganisms. In addition, phosphorus, which was a nutrient for the applied bacteria, could also be exhausted. The number of mesophilic bacteria in the final stage of logarithmic growth at $36^{\circ} \mathrm{C}$ was as much as $83,000,000 \times 10^{5} \mathrm{CFU} / \mathrm{cm}^{3}$, where at $21^{\circ} \mathrm{C}$, the colony was only $471,000 \times 10^{3} \mathrm{CFU} / \mathrm{cm}^{3}$ (Fig.3 and 4).

\subsection{Analysis of the amount of bioavailable phosphorus forms in sewage sludge}

To confirm changes in the amount of phosphorus - the active ingredient for bacteria, the amount of bioavailable forms in sewage sludge was analysed. The analysis of this element was carried out simultaneously with the determination of the number of mesophilic bacteria in the tested samples. Speciation analysis of phosphorus was made using the modified Golterman method. The bio-available fractions include the $\mathrm{Ca}$ EDTA and Na-EDTA fractions. The Ca-EDTA fraction makes it possible to distinguish phosphorus associated with oxides and hydroxides of elements such as aluminium, iron and manganese. In turn, the $\mathrm{Na}$ EDTA fraction identifies phosphorus associated with carbonates, which can be transformed into assimilable forms. In the diagrams (Fig.6 and 7), the phosphorus content in the bioavailable fractions for two different temperature variants is presented.

At $36^{\circ} \mathrm{C}$ (Fig.6), a significant increase in the CaEDTA fraction was already observed after 7 hours of the process. The simultaneous increase in the content of this fraction is accompanied by a decrease in the phosphorus content in the Na-EDTA fraction. On the second day, both fractions fall, while on the third day, the situation looks similar to the 7 hours of the process. On the fourth and eighth day, a significant increase in the Na-EDTA fraction for the Ca-EDTA fraction is observed.

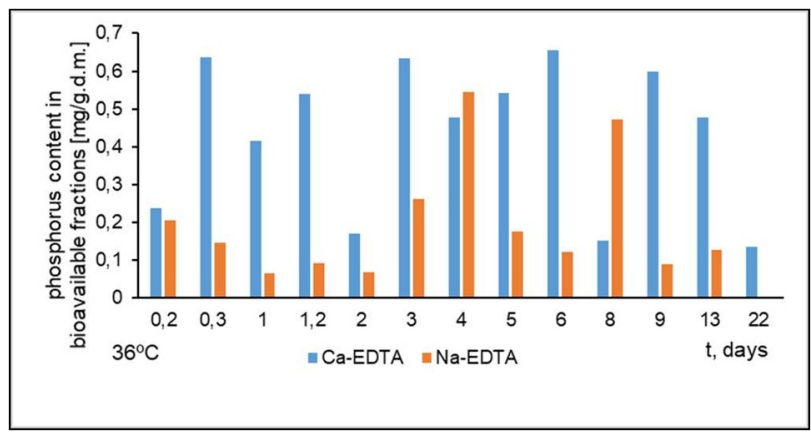

Fig. 6. Phosphorus content in bioavailable fractions at $36^{\circ} \mathrm{C}$

The highest content of phosphorus in the Ca-EDTA fraction occurs on the sixth day of the process (Fig. 6). This is related to the equilibrium phase shown in Figure 5 , where the number of bacteria is the highest, and the concentration of organic acids produced by them can be the highest. The significant increase in bio-available forms in the Na-EDTA fraction on the eighth day of the experiment is probably the result of changes occurring during the dieback phase (Fig.5). This phase releases phosphorus assimilated by microorganisms into the environment. In addition, significant drops in the $\mathrm{pH}$ of the tested suspension translate into an increase in the CaEDTA fraction. This is particularly evident on the first day of the process, where the $\mathrm{pH}$ has dropped from 9.69 to 6.04 (Fig.1 and 2). A similar situation occurs on the ninth day, when $\mathrm{pH}$ also decreased by 3 units (from 5.71 to 3.22). After this period, the $\mathrm{pH}$ stabilised, which translates into a simultaneous decrease in the phosphorus content in the Ca-EDTA fraction in the subsequent days of the experiment. The bacteria cease to produce organic acids. 
At $21^{\circ} \mathrm{C}$ (Fig.7), a significant increase in the NaEDTA fraction is observed in the initial phase of the process. The situation changes on the second day of the experiment, where the Na-EDTA fraction decreases in favour of the Ca-EDTA fraction. On the ninth day of observation, the process is more stable. It is assumed that this is associated with a drop in $\mathrm{pH}$ (Fig. 1 and 2) and the start of the logarithmic growth phase (Fig.5).

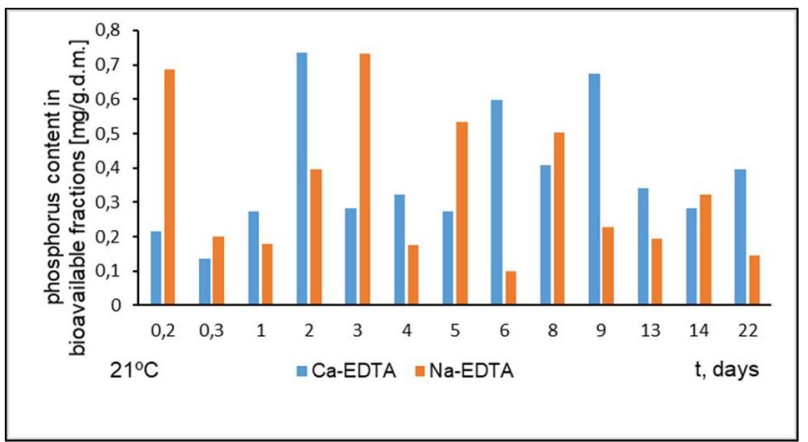

Fig. 7. Phosphorus content in bioavailable fractions at $21^{\circ} \mathrm{C}$

The obtained results (Fig.7) show that the process at a temperature of $21^{\circ} \mathrm{C}$ was slower compared to the test process at $36^{\circ} \mathrm{C}$ (Fig.6), where a significant decrease in the content of the Ca-EDTA fraction was visible on day 22 of the experiment.

When comparing both temperature conditions, it can be noticed that the process taking place at the lower temperature undergoes significant fluctuations. This may be due to the fact that a temperature of $21^{\circ} \mathrm{C}$ is not an optimal temperature for microorganisms of the genus Bacillus megaterium. In addition, a high dose of $\mathrm{CaO}$ and lack of mixing during the process can cause alternate death and growth of these microorganisms, which throughout the process try to adapt to the conditions they have undergone. This is due to the fact that microorganisms in this environment require higher energy consumption to dissolve sludge in the tested suspension, and this course can be additionally inhibited by the calcium oxide used for hygienisation. This is visible on the second day of the process at $36^{\circ} \mathrm{C}$ (Fig. 1 and 8), where the $\mathrm{pH}$ after a decrease of 3 units remains at a similar level, which in turn translates into a small phosphorus content in both fractions. In addition, a much higher content of the Ca-EDTA fraction was observed in samples kept in a heating furnace, while tests conducted at a lower temperature showed a higher content of the Na-EDTA fraction. It can therefore be concluded that the fraction of individual fractions depends on the temperature.

The observed changes in phosphorus specific forms indicate the process of its solubilisation and its differentiation depending on the temperature under the influence of organic acids produced by the studied microorganisms.

To illustrate the transformations of phosphorus forms in the studied sewage sludge, the percentage shares of all four fractions for two temperature conditions during the experiment were shown (Fig.8 and 9).

Analysis of Figure 8 confirms that on the sixth day of the process taking place at $36^{\circ} \mathrm{C}$, there are the most bioavailable forms (Ca-EDTA fraction). During this period, the phase of equilibrium begins, in which the metabolism of microorganisms is very intense. On the eighth day, the content of the Ca-EDTA fraction decreases, and in its place, there are phosphorus forms associated with carbonates (Na-EDTA fraction). This is related to the stage in which the microorganisms dissolve under the influence of acids produced in metabolic processes or pass into spore forms. The assimilated phosphorus is then released into the environment.

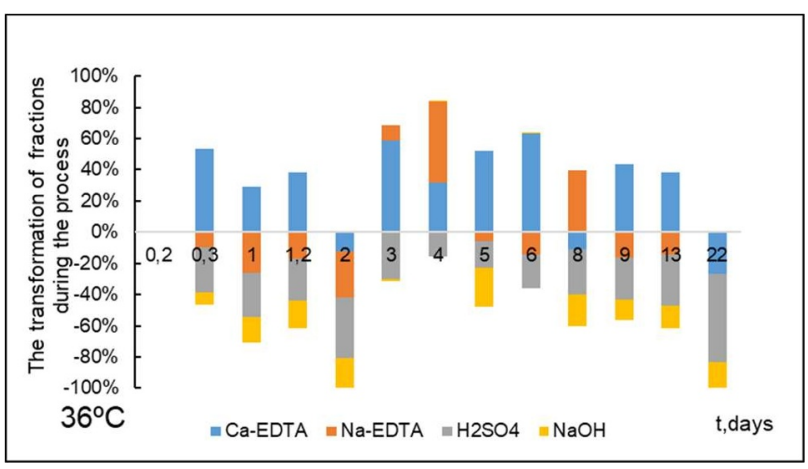

Fig. 8. Transformation of fractions during the process at $36^{\circ} \mathrm{C}$

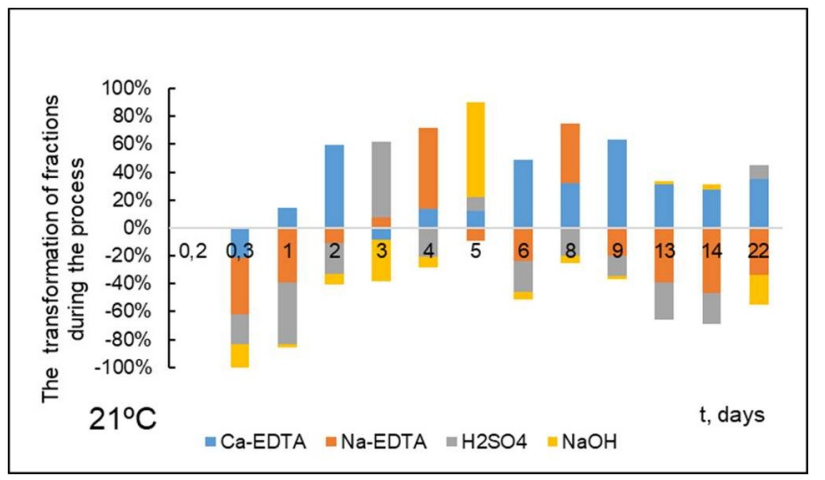

Fig. 9. Transformation of fractions during the process at $21^{\circ} \mathrm{C}$

In the case of the process running at $21^{\circ} \mathrm{C}$ (Fig. 9), it can be concluded that the highest percentages for the CaEDTA fraction, i.e. the most absorbable phosphorus fraction, fall on the ninth day of the experiment. The observed dependence is associated with a decrease in the $\mathrm{pH}$ level (Fig. 1 and 2), as well as the beginning of the logarithmic growth phase of mesophilic bacteria in the tested suspension (Fig.5). The high volatility in the shares of individual fractions is caused by the conditions selected for the needs of this experiment. High proportions of the $\mathrm{H}_{2} \mathrm{SO}_{4}$ fraction and $\mathrm{NaOH}$ in the initial period of the experiment ( 3 and 5 days) may be due to the strong alkaline reaction of the hygienised sludge. Under these conditions, sparingly soluble phosphorus salts can increase, which increase the fraction of these fractions. In addition, the lower temperature also has an impact on the reduction of the bacterial metabolic activity, which may result in a slower solubilisation process.

\subsubsection{Analysis of the amount of phosphorus assimilated by microorganisms}

The Ca-EDTA fraction was used to analyse the amount of phosphorus assimilated by the bacteria applied to the 
sludge. It allows us to isolate the most active and biologically available forms of phosphorus, which bind with oxides and hydroxides of aluminium, manganese and iron. These changes are shown in Figures 10 and 11 for two different temperature conditions.

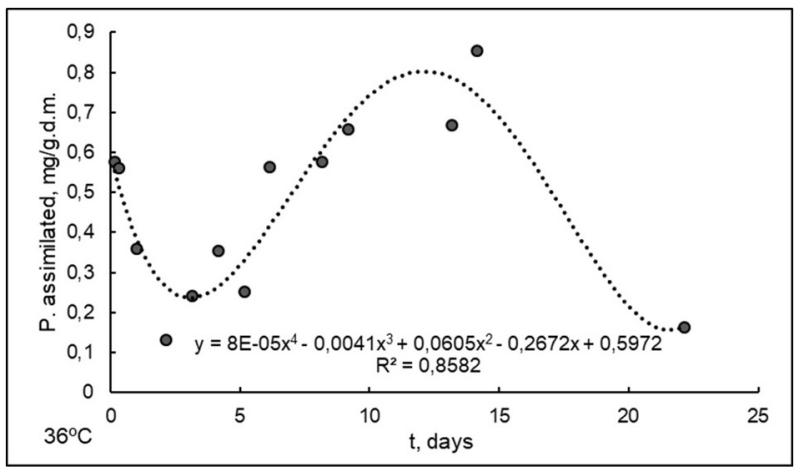

Fig. 10. Change in the amount of phosphorus assimilated at $36^{\circ} \mathrm{C}$

In the samples placed in the incubator, the bacteria took small amounts of phosphorus at the beginning of the process. Afterward, there was a drop, which lasted until the third day. This is related to the ongoing stagnation phase (Figure 5), where microorganisms have adapted to new conditions. After this time, there was an increase in the assimilation of this element, which lasted until the thirteenth day of the experiment, despite the decreasing number of bacteria (Fig. 4). This can be explained by the fact that not all microorganisms were at the same stage of development, and when some of them went into the phase of dieback, the next one started the logarithmic growth phase (Fig. 3 and 4).

Similarly to the experiment conducted at a higher temperature (Fig. 10), in the tests placed in the laminar chamber, there was a slight assimilation of phosphorus by microorganisms in the first hours of the process. After that time, there was a significant drop, which lasted until the fifth day. Assimilation of phosphorus began before the end of the stagnation phase and also continued during the stage of dieback bacteria (Fig.5).

Analysing both graphs (Fig. 10 and 11), it can be concluded that under both temperature conditions, the assimilation of phosphorus by microorganisms is undoubtedly taking place. At a temperature of $36^{\circ} \mathrm{C}$, this process takes place faster and also lasts a shorter time. It can therefore be concluded that a higher temperature has a better effect on its course. At the upper temperature, the microorganisms assimilated a total of $6.52 \mathrm{mgP} /$ g.d.m. during the process, while at a temperature of $21^{\circ} \mathrm{C}$ - $5.96 \mathrm{mgP} /$ g.d.m.

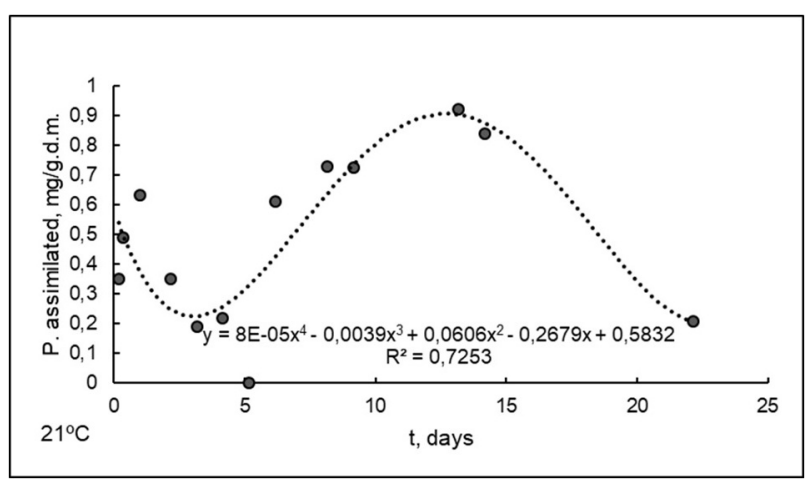

Fig. 11. Change in the amount of phosphorus assimilated at $21^{\circ} \mathrm{C}$

\subsection{Analysis of IR spectra of sludge}

The ability of Bacillus megaterium bacteria to assimilate phosphorus from the studied sewage sludge was confirmed by spectroscopic analysis. The recorded IR spectra of the sludge samples showed changes in transmittance in the wavenumber range of $1055 \mathrm{~cm}^{-1}$, where vibrations of phosphorus-containing groups (P-O$\mathrm{C}),(\mathrm{P}-\mathrm{O})$ occur. The obtained values of transmittance (Fig. 12, 13, 14 and 15) correlate with changes in the population of microorganisms (Fig.5) [3, 17]. After the first day of the process for $36^{\circ} \mathrm{C}$ (Fig.12), the transmittance of the oscillator bands increased significantly, which suggests that phosphorus was assimilated by microorganisms after the first day of the process, and the content of this fraction increased steadily up to the second day $[3,17]$. On day 3 , a significant decrease in transmittance was observed for the characteristic peak of the $1055 \mathrm{~cm}^{-1}$ wave number. This may be due to the fact that the bacteria were applied to a non-homogeneous mixture with a high dose of $\mathrm{CaO}$, which hindered the digestion of the tested sediment.

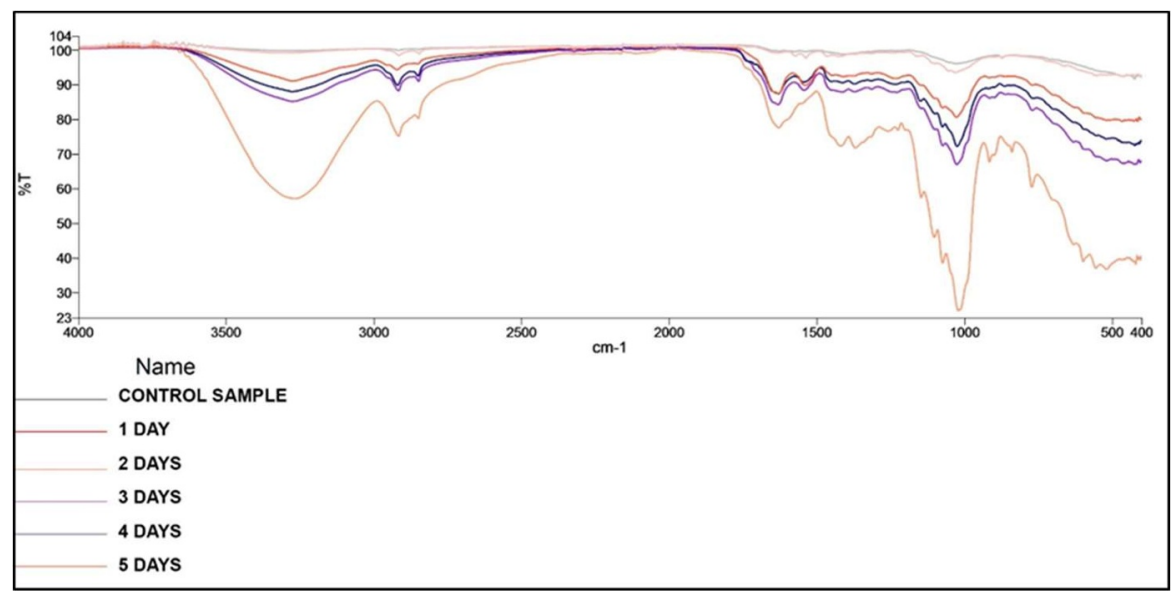

Fig. 12. FTIR spectra of the sediments tested during the first five days of the experiment at $36^{\circ} \mathrm{C}$ 


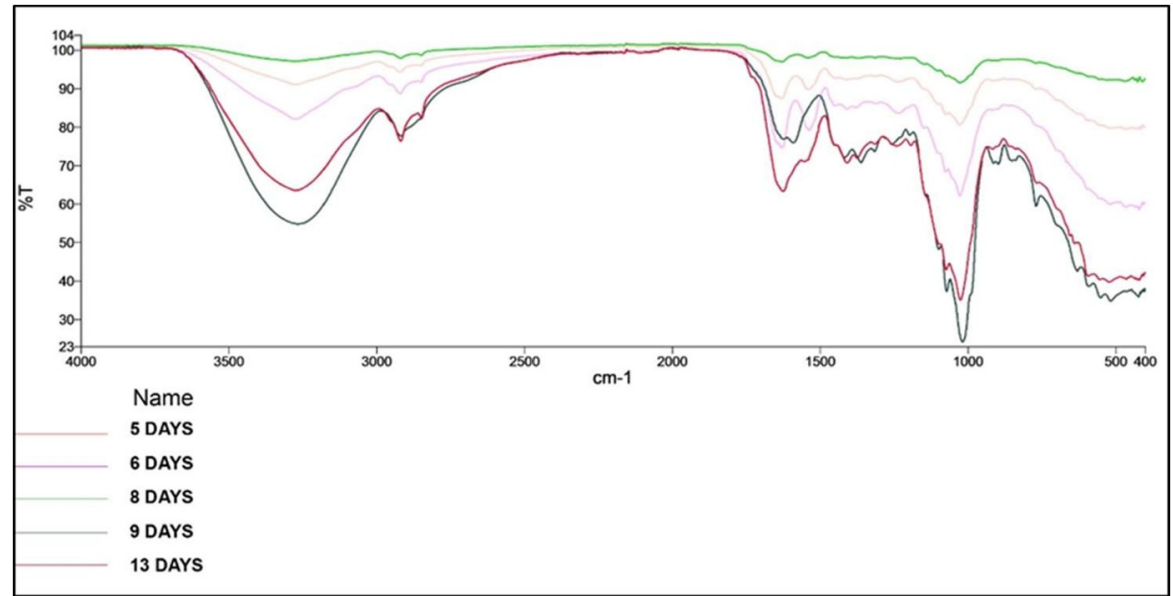

Fig. 13. FTIR spectra of the tested sediments during the $5^{\text {th }}, 6$ th, 8 th, 9 th and 13 th day of the experiment for the temperature of $36^{\circ} \mathrm{C}$

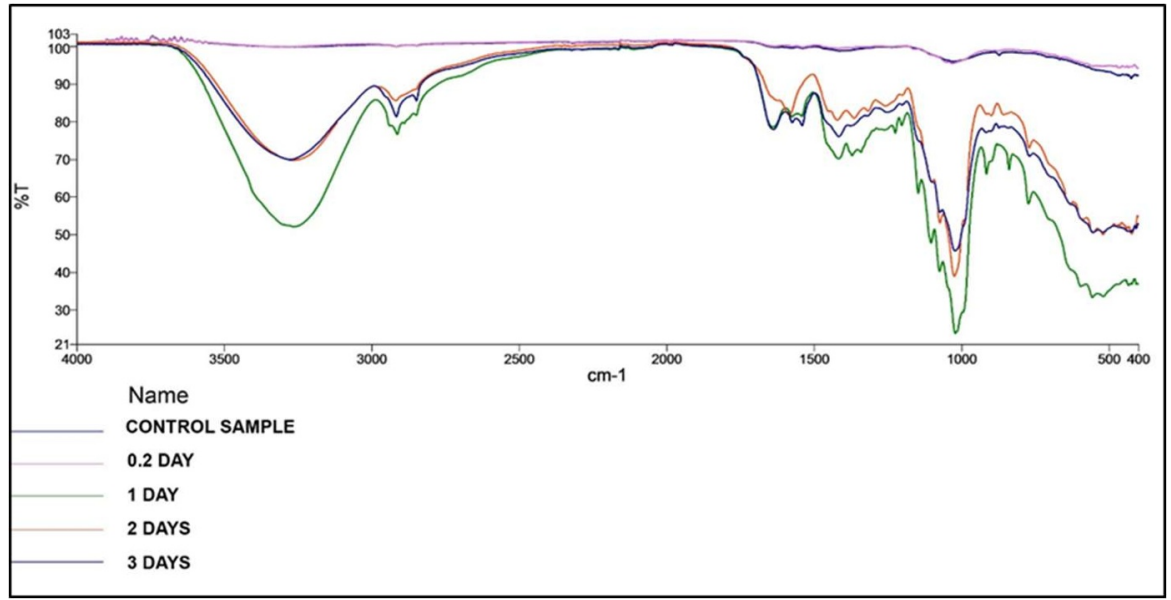

Fig. 14. FTIR spectra of the tested sediments during the 1 st, 2 nd and 3 rd day of the experiment at $21^{\circ} \mathrm{C}$

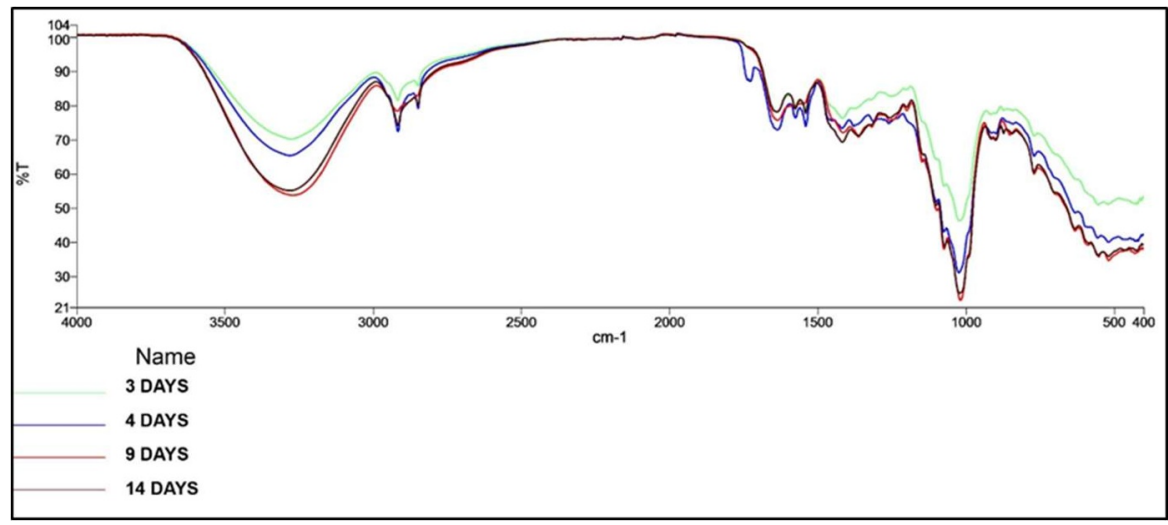

Fig. 15. FTIR spectra of the tested sediments over $3,4,9$ and 14 days of the experiment for the temperature of $21^{\circ} \mathrm{C}$

On the fifth day of the process (Fig. 13), transmittance increases up to 6 days, and after 8 days, a decline is noticed. This may be related to the fact that during the sixth day of the experiment, the logarithmic growth phase ended, and the equilibrium phase started (Fig.5). Lowering the concentration of chemical oscillators means that Bacillus megaterium bacteria assimilated the compounds contained in the studied sediment. In turn, after the eighth day of the experiment, there was a phase of dieback, which caused the release of phosphorus accumulated in the cells of the bacteria. After the eighth day of the process, a clear decrease in the transmittance value is observed, which is maintained until the end of the research. There are only slight variations between the ninth and thirteenth day. During this period, a transition from the phase of dieback to the dormant phase of microorganisms found in the tested suspension occurred (Fig. 5).

After the first day of the process at $21^{\circ} \mathrm{C}$ (Fig. 14), the bandwidth transmission increased; thus, there was a drop 
in the concentration of chemical oscillators, which lasted until the third day of the experiment. Afterward, the stagnation phase continued, where bacteria adapted to the new environment. It can therefore be concluded that the individual microorganisms assimilated the compounds contained in the stabilised sludge.

After the third day of the experiment (Fig.15), the transmittance was constantly increasing. However, these changes were not as pronounced as in the case of an experiment at $36^{\circ} \mathrm{C}$. The bacteria applied to the studied sediment are mesophilic microorganisms; therefore, the higher temperature was more conducive to their development, which also translated into greater assimilation of phosphorus.

\section{Conclusion}

The results obtained during the research allow us to formulate the following conclusions:

1. Bacteria of the genus Bacillus megaterium can solubilise phosphorus from sewage sludge, subjected to hygienisation with a large dose of calcium oxide. In addition, this process takes place at both $21^{\circ} \mathrm{C}$ and $36^{\circ} \mathrm{C}$. In both cases, the environment was acidified.

2. The presence of Bacillus megaterium caused the growth of mobile phosphorus forms in the studied settlement. Organic acids produced by these microorganisms have a positive effect on the course of solubilisation. When the $\mathrm{pH}$ drops, an increase in the bioavailable forms of phosphorus is noted at the same time.

3. Solubilisation of phosphorus occurs much faster at a higher temperature. The microorganisms used for the experiment are mesophiles, and they best grow at 35$37^{\circ} \mathrm{C}$. Therefore, the temperature rise is not stimulating, which in turn stimulates the metabolic processes to increase the secretion of enzymes. This is also confirmed by the fact that in the tests placed in the incubator $\left(36^{\circ} \mathrm{C}\right)$, there was a significant increase in the number of bacteria in relation to the experiment conducted in the laminar chamber $\left(21^{\circ} \mathrm{C}\right)$.

4. These microorganisms undoubtedly affect the amount of phosphorus speciation forms in the studied sediment. Cultivation at $21^{\circ} \mathrm{C}$ assimilated the phosphorus contained in the Ca-EDTA and Na-EDTA fractions; however, the forms contained in the organic matter $\left(\mathrm{H}_{2} \mathrm{SO}_{4}\right.$ and $\mathrm{NaOH}$ fraction) did not decompose. On the other hand, bacteria placed at $36^{\circ} \mathrm{C}$ accumulated both bioavailable (inorganic) forms and led to a partial decomposition of hard-to-reach forms of this element.

\section{Acknowledgements}

Publication supported by the Polish Ministry of Science and Higher Education as a part of the program of activities disseminating science from the project ,Organization of the First International Science Conference - Ecological and Environmental Engineering”, 26-29 June 2018, Kraków.

\section{References}

1. Biedendieck R., Bunk B.,et al., Biosys. Eng. I Creat. Sup. Biocat., 134-159 (2010)

2. Bezak-Mazur E., Stoińska R., Arch. of W. Managm. and Env. Prot. 15, 3, 33-42 (2013)

3. Bezak-Mazur E., Stoińska R., Szeląg B., S Arch. Civ. Eng. Env. 4, 81-87 (2015)

4. Bień J., Sewage sludge, theory and practice (Częstochowa Univ. of Tech., 2007)

5. Buczek J., K. Buczek K., Outline of general microbiology (Lublin, 2000)

6. Collective work, Chemistry: phosphorus compounds in chemistry, agriculture, medicine and environmental protection (Univ. of Eco. in Wroclaw, 2008)

7. Dhankhar, Sheoran, et al. IJDR. 3, 9, 31-36 (2013)

8. Khan M., Zaidi A., Oves M., Bacteria in agrobiology: crop productivity (Berlin, 2013)

9. Kurek E., Ozimek E. Adv. in Agr. Sci. 2, 85-95 (2008)

10. Labuda M., Saeid A., Chojnacka K., Górecki H., Przem. Chem., 91, 5, 837-840 (2012a)

11. Labuda M., Saeid A., Chojnacka K., Górecki H., Przem. Chem. 91, 5, 956-958 (2012b)

12. Mohammadi K., Res. and Env. 2, 1, 80-85 (2012)

13. Ociepa-Kubicka A., Pachura P., Rocz. Ochr. Środ. 15, 2267-2278 (2013)

14. Schlegel H.G. General microbiology (PWN, 2005)

15. Sharma S.B., Sayyed R.Z., Trivedi, M.H. Gobi T.A., Spr. P1. 2, 587, 1-14 (2013)

16. Spencer J., Spencer A., Environmental microbiology. Methods and protocols, (Met. in Biotech., 2004)

17. Szczepaniak W., Instrumental methods in chemical analysis, (PWN 2008). 